\title{
Unscrambling the effect of $C$-terminal tail deletion on the stability of a cold-adapted, organic solvent stable lipase from Staphylococcus epidermidis AT2
}

\begin{abstract}
Terminal moieties of most proteins are long known to be disordered and flexible. To unravel the functional role of these regions on the structural stability and biochemical properties of AT2 lipase, four C-terminal end residues, (Ileï Thrï Argï Lys) which formed a flexible, short tail-like random-coil segment were targeted for mutation. Swapping of the tail-like region had resulted in an improved crystallizability and anti-aggregation property along with a slight shift of the thermostability profile. The lipolytic activity of mutant (M386) retained by $43 \%$ compared to its wild-type with $18 \%$ of the remaining activity at $45{ }^{\circ} \mathrm{C}$. In silico analysis conducted at 25 and $45{ }^{\circ} \mathrm{C}$ was found to be in accordance to the experimental findings in which the RMSD values of M386 were more stable throughout the total trajectory in comparison to its wild-type. Terminal moieties were also observed to exhibit large movement and flexibility as denoted by high RMSF values at both dynamics. Variation in organic solvent stability property was detected in M386 where the lipolytic activity was stimulated in the presence of $25 \%(\mathrm{v} / \mathrm{v})$ of DMSO, isopropanol, and diethyl ether. This may be worth due to changes in the surface charge residues at the mutation point which probably involve in proteinï solvent interaction.
\end{abstract}

Keyword: C-terminal region; Deletion; Crystallizability; Thermostability; Organic solvent stability 